\title{
LA MÉTRICA DE ANDRÉS BELLO METER IN ANDRÉS BELLO
}

\author{
ESTEBAN TORRE \\ Universidad de Sevilla
}

Resumen: E1 15 de octubre de 2015 se cumplen 150 años de la muerte de Andrés Bello. En este trabajo - homenaje a la obra del ilustre filólogo venezolano- se estudia su original doctrina sobre la cantidad silábica, así como su concepción del verso como unidad rítmica, delimitada por la pausa final. Se lleva a cabo un detenido análisis comparativo con las ideas métricas de diversos autores de los siglos XIX y XX, partiendo de los precedentes de los siglos XV-XVIII.

Palabras clave: Andrés Bello, métrica, historia de la métrica, cantidad silábica, finales de verso agudos, graves y esdrújulos, endecasílabo sáfico.

Abstract: October 15th, 2015, marks the 150th anniversary of the death of Andrés Bello. In this tribute study of the work of the prestigious Venezuelan philologist, his individualistic doctrine on syllabic quantity is analyzed, together with his conception of the verse-line as a rhythmic unit marked off by an end-pause. A close comparative analysis is undertaken with the ideas on meter of a range of nineteenth and twentieth-century authors, while using as a 
point of departure those who belong to the period spanning the fifteenth to the eighteenth centuries.

Keywords: Andrés Bello, meter, history of meter, syllabic quantity, final-syllabe, penultimate-syllable, and antepenultimate-syllabe line-ending accents, Sapphic hendecasyllable. 


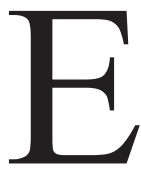

115 de octubre de 2015 se cumplen 150 años de la muerte de Andrés Bello (1781-1865) en Santiago de Chile. Había nacido el ilustre filólogo, metrista, poeta, traductor, filósofo, ensayista, político, diplomático y jurista venezolano en la ciudad de Caracas el 29 de noviembre de 1781. Desde 1810 hasta 1829, reside en Londres, donde fue redactor del periódico El Español, relacionándose con personajes del mundo de las letras, como José María Blanco-White, Vicente Salvá o Bartolomé José Gallardo, y de la política, como Antonio José de Irisarri, encargado de negocios de Chile, o Francisco Antonio Pinto, futuro presidente de esta nación hispanoamericana. Abandona Inglaterra el 14 de febrero de 1829, trasladándose a Chile, donde permanece hasta su muerte, y donde llegó a obtener la nacionalidad chilena, el puesto de senador por la ciudad de Santiago y el cargo de primer rector de la Universidad de Chile.

En 1981, bicentenario de su nacimiento, fue objeto de diversos homenajes en las dos orillas del Atlántico. Los días 3 y 4 de ese año, tuvo lugar una mesa redonda en torno a la obra del gran humanista en los departamentos de español de Ámsterdam y de Utrecht, y las comunicaciones presentadas se publicaron oportunamente en un volumen del Spaans Seminarium de Ámsterdam ${ }^{1}$. Del mismo modo, el Centro de Lingüística Hispánica, del Instituto de Investigaciones Filológicas de la Universidad Nacional Autónoma de México, le rindió homenaje durante los

\footnotetext{
${ }^{1}$ Homenaje a Andrés Bello en el bicentenario de su nacimiento (1781-1981), Diálogos hispánicos de Amsterdam, $n^{\circ} 3$. Amsterdam: Rodopi, 1982. Se tratan diversos aspectos de los estudios gramaticales, filosóficos, jurídicos y de crítica literaria. Un artículo de Antonio Quilis se ocupa de la «Vigencia de las teorías ortológicas y métricas de Bello».
} 
días 7 y 8 de diciembre de $1981^{2}$. También el Instituto de Chile se sumó a esta serie de merecidos homenajes ${ }^{3}$.

Las páginas que se dedican aquí y ahora a su recuerdo están centradas en la doctrina métrica sostenida por Andrés Bello en su obra Principios de la ortología y métrica de la lengua castellana, editada por vez primera en $1835^{4}$. La métrica de Bello supone, como tendremos ocasión de ver, un poderoso avance hacia la modernidad, en especial en lo que se refiere a las ideas vigentes en su tiempo sobre la cantidad silábica, el verso como unidad rítmica y la cuestión de los finales agudos graves y esdrújulos. En el prólogo de la edición de 1835, nos advierte el autor que creyó conveniente añadir a la Ortología, «que comprende, como parte integrante, la doctrina de los acentos y las cantidades, llamada comúnmente Prosodia», un tratado de Métrica, ya que «la Prosodia y la Métrica son dos ramos que ordinariamente van juntos, porque se dan la mano y se ilustran recíprocamente». Y explica:

En la Métrica doy un análisis completo, aunque breve, del artificio de nuestra versificación, y de los verdaderos principios o elementos constitutivos del metro en la poesía castellana, que bajo este respecto tiene grande afinidad con la de casi todas las naciones cultas modernas. Pero me era imposible emprender este análisis sin que me salie-

${ }^{2}$ Lope Blanch, Juan Miguel (ed.): Homenaje a Andrés Bello. México: UNAM, 1983. En varios artículos, se estudian distintos aspectos gramaticales, tales como la teoría de los tiempos, los nexos, los pronombres y adverbios relativos, o la reforma ortográfica. No hay ninguna referencia a las cuestiones de ortología y métrica.

${ }^{3}$ Homenaje a don Andrés Bello. Santiago: Instituto de Chile, 1982. Sólo un artículo de Ambrosio Rabanales, «Vigencia de las ideas lingüísticas y gramaticales de don Andrés Bello», se ocupa de las cuestiones filológicas. No se menciona la métrica.

${ }^{4}$ Bello, Andrés: Principios de la ortolojía i métrica de la lengua castellana. Santiago de Chile: Imprenta de la Opinión, 1835. Nuevas ediciones en Santiago de Chile: Imprenta del Progreso, 1850; Imprenta de la opinión, 1859. Reediciones en Caracas y Bogotá. Obras completas en Santiago de Chile, Madrid y Caracas: Obras completas de don Andrés Bello. Santiago de Chile: Imprenta de Pedro G. Ramírez (tomos I-XIII), 1881-1890; Imprenta Cervantes (tomos XIV-XV), 1891-1893. Obras completas. Opúsculos gramaticales I. Principios de la ortología y métrica de la lengua castellana. Madrid: Tello, 1890 (todas las citas de la Ortología y métrica se harán por esta edición). Obras completas. Estudios filológicos I. Principios de la ortolojía i métrica de la lengua castellana (con una «Introducción a los estudios ortológicos y métricos de Bello» de Samuel Gili Gaya). Caracas: Biblioteca Nacional, 1954. Obras completas. Caracas: Fundación La Casa de Be1lo, 1981-1986. 
sen al paso las reñidas controversias que han dividido siglos hace a los humanistas, acerca de las cantidades silábicas, el oficio de los acentos y la medida de los versos. Después de haber leído con atención no poco de lo que se ha escrito sobre esta materia, me decidí por la opinión que me pareció tener más claramente a su favor el testimonio del oído. [...] No disimularé que mi modo de pensar está en oposición absoluta con el de dos eminentes literatos, autor el uno [José Gómez Hermosilla] de un excelente tratado de literatura y traductor de Homero, y recomendable el otro [Mariano José Sicilia] por la publicación de los primeros elementos de Ortología que se han dado a luz sobre la lengua castellana.

Desde el comienzo de su obra, se muestra Andrés Bello preocupado por la cuestión central de la Métrica, que no es otra que «la medida de los versos», así como por «el oficio de los acentos» en las secuencias rítmicas y «las reñidas controversias» sobre una hipotética pervivencia de «las cantidades silábicas», esto es, la existencia o no en la lengua española de sílabas largas y breves. También desde el principio, acude al «testimonio del oído» como a la más fiable fuente de opinión.

En la primera mitad del siglo XIX, las ideas imperantes sobre esta materia eran las mantenidas en el siglo anterior en la Poética de Ignacio de Luzán, publicada por primera vez en Zaragoza en 1737, y nuevamente en Madrid en 1789, como edición póstuma, corregida y aumentada por su mismo autor. Escribe Luzán que «en las lenguas Española e Italiana, el acento agudo suple en cierto modo la cantidad, y hace que la sílaba parezca larga». Admite que la pronunciación «no se conserva ya en las lenguas vulgares tal como fue en la Griega y Latina», y que se ha perdido «aquella tan cabal y delicada distinción con que las sílabas largas se pronunciaban en dos tiempos, y las breves en uno». pero, con todo, no puede acabar de creer que «nuestra pronunciación (hablo de Españoles e Italianos) quanto a las largas y breves sea totalmente diversa de la antigua, de modo que no haya quedado alguna distinción bastante para la harmonía poética» ${ }^{5}$.

La identificación de las sílabas tónicas con las largas, y las átonas con las breves, es un prejuicio que en cierto modo ha llegado hasta nuestros días, no sólo en la aclimatación de los

${ }^{5}$ LuzÁn, Ignacio de: La Poética, o reglas de la poesía en general, y de sus principales especies. Ed. corregida y aumentada. Tomo I. Madrid: Sancha, 1789, pp. 328-336. 
pies métricos grecolatinos (yambos, troqueos, dáctilos, etc.) a los actuales pies o cláusulas rítmicas, sino también en el cómputo silábico de las terminaciones agudas y esdrújulas, otorgándosele a la tónica final de la terminación aguda el valor de dos tiempos silábicos, $\mathrm{y}$, a las dos sílabas postónicas de la terminación esdrújula, el valor de un solo tiempo silábico.

Ya a finales del siglo xV, Juan del Encina había identificado las sílabas breves con las átonas y las largas con las tónicas: «Y avemos de notar que sílabas breves en el romance llamamos todas las que tienen el acento baxo, y luengas o agudas se dizen las que tienen alto el acento» ${ }^{6}$. Considera Juan del Encina como luenga la última sílaba de los versos con final agudo, y así cuenta una sílaba más «quando la última es luenga, que entonces vale por dos, y tanto tardamos en pronunciar aquella sílaba como dos» ${ }^{7}$.

Un siglo más tarde, Juan Díaz de Rengifo compara en el capítulo XIX de su Arte poética los siguientes versos: «las flores odoríferas» y «el árbol que se trasplantó». Cada uno tiene ocho sílabas -escribe- y no por eso son versos octosílabos o «de redondilla». La razón es que «faltó el acento en la penúltima, que había de ser larga»:

No basta que el verso tenga las syllabas que le conuienen, y que no tenga mas, ni menos, si no es menester que lleue la quantidad, que dentro de su especie pide. Porque si esta faltasse, aunque vuiesse todo lo demás no seria verso. Este verso, Las flores odoriferas, y este, el arbol que se trasplanto, tienen cada uno ocho syllabas, y no por esso son versos de Redondilla; porque falto el accento en la penultima, que auia de ser larga ${ }^{8}$.

Los dos versos citados constan realmente, o gramaticalmente, si se quiere, de ocho sílabas; pero, rítmicamente, el primero sólo tiene siete, mientras que el segundo alcanza la cifra de nueve. No son octosílabos por lo tanto, no son versos «de redondilla». Para

\footnotetext{
${ }^{6}$ ENCINA, Juan del: Arte de poesía castellana (1496), en LÓPEZ ESTRADA, Francisco (ed.): Las poéticas castellanas de la Edad media. Madrid: Taurus, 1984, pp. 89-90.

7 Ibid., p. 87.

${ }^{8}$ Diaz Rengifo, Juan: Arte poética española. Salamanca: Miguel Serrano de Vargas, 1592, p. 21.
} 
explicar esta circunstancia métrica acude Rengifo a la «quantidad», confuso recuerdo de la calidad de las sílabas, largas y breves, de las lenguas clásicas.

Los prestigiosos tratados de poética del renacimiento italiano abundan en la misma visión de la cantidad silábica. Así, en las Prose della volgar lingua $(1525)$ de Pietro Bembo, se afirma que en nuestro vulgar siempre es larga la sílaba portadora del acento, y breves las demás. En los versos agudos, la sílaba final pesa mucho y vale por dos; de ahí que haya de contarse una sílaba más. Por el contrario, en los esdrújulos, las sílabas finales son ligeras, y hay que contar una sílaba menos ${ }^{10}$.

En la Poetical ${ }^{11}$ (1529 y 1562), una de las principales obras en lengua toscana del humanista italiano Giovan Giorgio Trissino, se sostiene que es breve la sílaba que «se profiere en poco espacio de tiempo», y larga «la que en más», de tal manera que «se tarda tanto en proferir una sílaba larga como dos breves». Piensa el tratadista que en la lengua toscana sigue habiendo sílabas largas y breves, y que «todo aquel que quiera considerar la longitud y brevedad de algunas sílabas, tanto graves como agudas, extraerá mucha utilidad de tal cosa y dará mucho ornamento a sus poemas»> ${ }^{12}$.

Antonio Sebastiano Minturno, en su tratado L'arte poetica ${ }^{13}$, advierte que al final del verso «crece una sílaba el esdrújulo, y falta una sílaba en aquel que lleva el acento en la última». En consecuencia, en el esdrújulo «dos sílabas valen por una», y en el agudo la última sílaba «vale por dos». Por lo que respecta a los pies métricos, considera que los toscanos pueden hacer versos del mismo modo que los hicieron los griegos y los latinos. Así, los dáctilos son conjuntos de tres sílabas, de las

${ }_{9}^{9}$ Bembo, Pietro: Prosas de la lengua vulgar. Ed. bilingüe. Trad. esp. de Oriol Miró Martí. Madrid: Cátedra, 2011.

10 Vid. PARAíso, Isabel: «Las teorías métricas de Pietro Bembo en las Prose della volgar lingua (Prose nelle quali si ragiona della volgar lingua». Rhythmica, Revista Española de Métrica Comparada, 2012, X, 12, pp. 133-155.

11 Trissino, Giovan Giorgio: La Poética. Ed. bilingüe. Trad. esp. y estudio de Isabel Paraíso. Madrid: Arco/Libros, 2014.

12 Vid. Torre, Esteban: «Giovan Giorgio Trissino: La Poética». Rhythmica, Revista Española de Métrica Comparada, 2014, XII, 12, pp. 211-215.

13 Minturno, Antonio Sebastiano: Arte poética. Ed. bilingüe. Trad. esp. y estudio de $\mathrm{M}^{\mathrm{a}}$. del Carmen Bobes Naves. Madrid: Arco/Libros, 2009. 
cuales la primera es larga (tónica) y las otras dos breves (átonas), tales como scriuere, candido, pessimo. Los anapestos constan de dos sílabas breves y una final larga, como validi. Identificando una vez más las sílabas tónicas con las largas, señala que, en la lengua toscana, la penúltima sílaba de toda palabra llana ha de ser considerada siempre como larga: ardeva, signore, sedere. $\mathrm{Si}$ el pie bisilábico lleva larga la sílaba primera y breve la segunda, como legge, finge, vista, recibe el nombre de troqueo. Sería el pie más frecuente de la lengua toscana ${ }^{14}$.

El conflicto entre la métrica silábico-acentual de las lenguas vernáculas, de raíces medievales, y la métrica cuantitativa, de corte latinizante y helenizante, defendida por los humanistas, da origen a distintas querellas, que se formulan y entablan en el renacimiento europeo entre los antiguos y los modernos. Destaca entre ellas la que tuvo lugar en la Inglaterra isabelina en torno al uso del verso rimado. Se podría pensar, tal vez, que la modernidad habría de estar del lado del humanismo renacentista. Pero no es así. Lo nuevo, lo moderno, es lo gótico, lo medieval; mientras que las actitudes renacentistas suponen una vuelta al pasado, a lo antiguo.

Paradigma de esta apasionada polémica entre antiguos y modernos es la entablada en Inglaterra, en los albores del reinado de Jacobo I Estuardo, entre Thomas Campion y Samuel Daniel. En 1603, publica Samuel Daniel una Defence of Ryme en abierta oposición a las Observations in the Art of English Poesie, de Thomas Campion, impresas un año antes ${ }^{15}$. Para Thomas Campion, en la poesía, es fundamental el número (number), entendido no sólo como mero cómputo silábico, sino como expresión de. la calidad (value) de los sonidos largos o breves (the length or shortness of their sound), esto es, la cantidad silábica. La naturaleza cuantitativa del verso, escrupulosamente respetada por los griegos y los romanos, habría sido lastimosamente deformada tras la invasión de los bárbaros y la corrupción de la lengua latina. La incapacidad de los poetas para seguir, en su

${ }^{14}$ Vid. TORRE, Esteban: «La métrica de Minturno». Rhythmica, Revista Española de Métrica Comparada, 2010, VIII, 8, pp. 191-217.

15 Vid. Daniel, Samuel: Defensa de la rima. Ed. bilingüe. Trad. esp. y estudio de Juan Frau. Prólogo de Esteban Torre. Valladolid: Universidad, 2011. 
lengua vernácula, los criterios cuantitativos habría dado lugar al uso de la rima. De ahí que sería un gran honor para la lengua inglesa que, después de tantos años de barbarie, se restaurara la versificación cuantitativa de los griegos y los romanos.

Samuel Daniel niega que los metros utilizados por los poetas ingleses sean defectuosos, así como que toda rima haya de ser grosera, vulgar y bárbara. Si los versos griegos y latinos se basaban en el número y en la cantidad silábica (number and quantitie of syllables), los versos ingleses se sustentan en la medida y el acento (measure and accent). Las sílabas de acentuación aguda, tónicas, y las sílabas de acentuación grave, átonas, harían el papel de largas y breves respectivamente.

Por su parte, la actitud de Andrés Bello ante la medida del verso es bien clara y sencilla. El oído ha de ser siempre nuestro guía para la percepción de las sílabas y los acentos. En el capítulo IV de la parte I, «De las sílabas», una nota inicial nos indica que «para la debida inteligencia de éste y los siguientes capítulos, conviene que el alumno aprenda a percibir por el oído la medida de los versos octosílabo y endecasílabo». Este primordial adiestramiento resultará ser fácil y sólo requerirá un corto ejercicio. Pero «el que no lo consiga, perderá el tiempo en el estudio de la prosodia y métrica».

Para Bello, no existen en castellano sílabas largas y breves, en el sentido de que una sílaba larga valga por dos breves. Las combinaciones de sonidos que llamamos sílabas «aunque no se pronuncian en tiempos exactamente iguales, se acercan con todo a la razón de igualdad en sus cantidades o duraciones». Es por eso por lo que «constando $a$ de un solo elemento, y siendo cons una de las sílabas más complejas que tiene el habla castellana, sin embargo $a$ y cons distan menos de la razón de igualdad que de la razón de 1 a $2 »^{16}$.

No distingue Bello entre sílabas tónicas y átonas, sino entre sílabas agudas y graves: «Las vocales acentuadas se llaman agudas, y las inacentuadas graves $\rangle^{17}$. El acento interviene en la

\footnotetext{
${ }^{16}$ Bello, Andrés: Principios de la ortología y métrica de la lengua castellana. Madrid: Tello, 1890, p. 134-136.

17 Ibid., p. 153.
} 
duración de la sílaba; pero, en cualquier caso, no han de identificarse las agudas con las largas, y las graves con las breves:

La duración de las sílabas depende del número de elementos que entran en su composición y del acento. Así, en las cuatro sílabas de que consta la dicción transcribiese, es indudable que la primera, trans, requiere más tiempo que la segunda, cri, por componerse aquélla de cinco elementos y ésta de tres; y no es menos cierto que la sílaba bié, compuesta de tres elementos, uno de los cuales es la vocal acentuada é, se pronuncia en más tiempo que la cuarta, se, que se compone de una sola consonante y una sola vocal que carece de acento. A pesar de estas diferencias, las duraciones o cantidades en todas las sílabas castellanas se acercan más a la razón de igualdad que a la de 1 a $2^{18}$.

En el Apéndice IX de la Ortología y métrica, «Sobre la teoría del metro», incide una vez más sobre el problema de la duración de las sílabas en castellano: «Las tiene largas y breves, porque es innegable que no todas consumen exactamente igual tiempo». Pero, se pregunta, ¿cuánto mayor es la duración de las largas? Y responde que no alcanza a determinarlo. En todo caso, «lo seguro es que las largas están a las breves en una relación mucho más cercana a la igualdad que a la de 2 a $1 »^{19}$.

Los «dos eminentes literatos» aludidos en el prólogo de la primera edición de la Ortología y métrica, José Gómez Hermosilla y Mariano José Sicilia, son directamente señalados en el ApéndiceVI, «Sobre la cantidad prosódica»:

En el Arte de hablar de D. José Gómez Hermosilla, y en las Lecciones de ortología y prosodia de D. Mariano José Sicilia, se inculcan ideas muy opuestas a las mías acerca de las cantidades o duraciones relativas de las sílabas castellanas. [...] Pero en lo que más me parece flaquear la teoría prosódica de este erudito escritor es en la evaluación relativa de las breves y largas. La larga, según el Sr. Hermosilla, dura dos tiempos; la breve, uno. Yo no veo que esto se nos haga sensible en el mecanismo de los versos castellanos, o se pruebe de cualquier otro modo. De que una sílaba se pronuncie más rápidamente que otra no se deduce que haya entre ellas la razón particular de 1 a 2 . [...] Comparemos estos dos vocablos: remedó y remendó. Men es sin duda más largo que me; pero ciertamente las dos duraciones no están en relación de 2 a $1^{20}$.

${ }_{18}$ Ibid., pp.199-200.

19 Ibid., pp. 435.

${ }^{20}$ Ibid., pp. 395-398. 
D. Mariano José Sicilia divide las sílabas en breves, más breves, largas y más largas. [...] La clasificación toda adolece del defecto gravísimo de no poderse comprobar por la práctica de los poetas, que debe ser la piedra de toque de toda teoría prosódica ${ }^{21}$.

En efecto, José Gómez Hermosilla sostenía en 1826, en su Arte de hablar en prosa y verso, que, «aunque nosotros no medimos los tiempos tan compasadamente como los antiguos, no prescindimos de ellos ni podemos prescindir» ${ }^{22}$. Y no le cabe la menor duda de que la $o$ de orar es breve, mientras que la $o$ de obstar es larga, «prueba irrefragable de que, además del acento, hay otra cosa que puede hacer largas las sílabas $\rangle^{23}$. Hermosilla da por supuesto que las sílabas acentuadas son largas.

Mariano José Sicilia, por su parte, sostenía en 1832, en sus Lecciones elementales de ortología y prosodia, que han sido muy diversos los pareceres de los autores sobre la cantidad silábica en la lengua castellana, «hasta el extremo de haber habido quien diga que nosotros no tenemos breves ni largas, [...] o que sólo eran largas las que llevaban el acento $\rangle^{24}$. Las sílabas pueden ser breves, más breves, largas y más largas, según que ocupen un solo tiempo, menos de un solo tiempo, un tiempo y parte de otro, y dos tiempos ${ }^{25}$. En la lengua castellana, «la cantidad de las sílabas proviene de dos solas causas, a saber: $1^{\circ}$. Del material ortológico de cada sílaba. $2^{\circ}$. De la ley del acento predominante de la dicción $»^{26}$. En cada sílaba, «la sencillez o la pesadez» depende del número de sonidos que la compongan. Cuanto mayor sea éste, «mayor habrá de ser necesariamente la porción de tiempo que se invierta en pronunciarlas» ${ }^{27}$. Es larga «toda silaba afectada por el acento predominante», y son breves «todas las sílabas que se siguen a la que lleva el acento predominante, aunque por su naturaleza sean largas ${ }^{28}$.

Ibid., pp. 401-405.

22 Gómez Hermosilla, Josef: Arte de hablar en prosa y verso. Tomo II. Madrid: Imprenta Real, 1826, p. 109.

23 Ibid., p. 120.

${ }^{24}$ Sicilia, Mariano José: Lecciones elementales de ortología y prosodia. Madrid: Imprenta Real, 1832, p. VII.

${ }^{25}$ Ibid., p. 14.

${ }^{26}$ Ibid., p. 17.

${ }^{27}$ Ibid., pp. 17-18.

${ }^{28}$ Ibid., pp. 41-43. 
En relación con el problema de la equivalencia de los finales agudos, graves y esdrújulos en el verso, rebate Andrés Bello, en el Apéndice VII de sus Principios de ortología y métrica, las teorías de Francisco Martínez de la Rosa y de Vicente Salvá:

D. Francisco Martínez de la Rosa, que en una de las notas a su Poética ha comparado la versificación antigua con la moderna (y a mi parecer más acertadamente que Hermosilla y Sicilia), encuentra un vestigio de aquella compensación de largas y breves, que era de necesidad absoluta para el ritmo antiguo, en la sílaba de menos que tienen constantemente nuestros verso agudos, y la sílaba de más que ponemos siempre a los esdrújulos. «La palabra trémula consume a fin de verso los mismos tiempos que la palabra fuerte». Pero ¿por qué sólo a fin de verso? [...] ¿No indica esto con toda claridad la influencia de la pausa, que hace de poca importancia las desigualdades de duración entre los finales graves, agudos y esdrújulos? Cuando en el final de un verso pongo el esdrújulo tenérsela en lugar de los graves tenerla o tenerse, ¿se podrá buenamente decir que se sustituyen dos breves a una larga? Es claro que no. [...] Y cuando sustituyo el final agudo tener al grave tenerle, ¿sustituyo acaso una larga a dos breves? Sin duda que no, porque lo mismo absolutamente es el ner en tener que en tenerle. [...] El tiempo que de este modo sobra, o falta, se embebe o suple en el reposo final del verso. [...] Son, pues, desiguales las duraciones de tenérsela, tenerse y tener, gastándose en la primera un tiempo más que en la segunda, y en la segunda un tiempo más que en la tercera. Si no se paliase esta desigualdad en el reposo con que termina el verso, no se toleraría.

D. Vicente Salvá explica de otro modo la aparente equivalencia de los finales agudo, grave y esdrújulo; pero no con mejor suceso. Según este docto filólogo, no hay verdaderamente dicciones agudas ni esdrújulas en castellano: todas son graves. Pronúncianse (dice) desdén, vendrá como si estuviesen escritos desdéen, vendráa. Por el contrario (añade), en los esdrújulos pasamos tan de corrida sobre la vocal de la sílaba media, que no se la percibe (son palabras textuales); de manera que pronunciamos línea, máxima casi como si estuviesen escritos lina, maxma $^{29}$.

Francisco Martínez de la Rosa, que representa tal vez el más firme baluarte en la defensa de la tesis cuantitativa, llega a afirmar en 1831, en distintos lugares de las notas a su Poética, que «los acentos son los que mejor nos indican la cantidad de las

${ }^{29}$ Bello, Andrés: Principios de la ortología ..., cit., pp.406-407. 
sílabas, es decir, las que son largas o breves $»^{30}$, que «la cantidad de las sílabas, y no su simple número, influye en la versificación moderna más de lo que comúnmente se imagina $)^{31}$, y que, en definitiva, son los acentos los que «distinguen las sílabas largas de las breves $\rangle^{32}$. En cuanto a la terminaciones agudas, graves y esdrújulas, «todo verso que acaba con acento agudo debe tener una sílaba menos que si acabase con grave; y todo el que acaba en palabra esdrújula (es decir, con acento agudo en la antepenúltima sílaba, siendo las dos últimas breves) debe tener una sílaba más» ${ }^{33}$. Así, la palabra trémula «aunque conste de tres sílabas, consume al fin del verso los mismos tiempos musicales que la palabra fuerte, que tiene sólo dos sílabas» ${ }^{34}$.

Vicente Salvá, en su Gramática de la lengua castellana (1830), nos dice que «en las palabras que acaban por una vocal aguda, hace la voz una especie de compensación duplicándola», y así «pronunciamos desdén, vendrá como si estuviera escrito desdén, vendráà»; en cambio, «en los esdrújulos pasamos tan de corrido por la sílaba media entre la acentuada y la última que no se percibe, de modo que pronunciamos línea, máximo casi como si estuviese escrito lina, maxmo ${ }^{35}$. Por otra parte, asegura que «los autores que han escrito de la prosodia española han observado, desde los más antiguos, que también tenemos nosotros sílabas largas y breves, acentuadas o agudas y graves, y que no es indiferente emplear éstas o las otras para que el verso conste ${ }^{36}$.

Frente a las opiniones de José Gómez Hermosilla, Mariano José Sicilia, Francisco Martínez de la Rosa y Vicente Salvá, autores coetáneos de Andrés Bello, expresa una y otra vez el maestro venezolano su oposición absoluta a la pertinencia métrica de los criterios cuantitativos, ya que es del todo irrelevante la mayor o menor duración de las sílabas, que en cualquier caso distan más de la razón de 1 a 2 que de la razón de igualdad. Por lo que

\footnotetext{
${ }^{30}$ Martínez de la Rosa, Francisco: Poética. Palma: Villalonga, 1831, p.162.

31 Ibid., p. 164.

32 Ibid., p. 177.

33 Ibid., pp. 164-165.

34 Ibid., p. 165.

35 SALvé, Vicente: Gramática de la lengua castellana según ahora se habla. Ed. de Margarita Lliteras. Madrid: Arco/Libros, p. 789.

${ }^{36}$ Ibid., p. 787.
} 
respecta a la equivalencia de los finales agudos, graves y esdrújulos, rechaza que la última sílaba del final agudo valga por dos, porque esto no sería más que un pretendido «vestigio» de la versificación antigua. Si la sílaba ner de tener hubiera de valer por dos, también habría de valer por dos la sílaba ner de tenerle, o la sílaba ner de tenérsela. Tan aguda, larga o acentuada sería esta sílaba en la palabra aguda como en la llana o en la esdrújula. Para Andrés Bello, la explicación del fenómeno de la equivalencia residiría en «la influencia de pausa», que hace «de poca importancia» las desigualdades de duración entre los finales agudos, graves o esdrújulos. En virtud de la pausa, la sílaba que sobra en el esdrújulo, o falta en el agudo, «se embebe o suple en el reposo final del verso». Tampoco se sostiene la teoría de Salvá, según la cual todas las palabras serían llanas en castellano.

En esta misma línea, Luis de Mata y Araujo afirma en 1839, en sus Lecciones elementales de literatura, que «las naciones modernas, y entre ellas la nuestra, no haciendo percibir en la pronunciación tan distintamente la cantidad de las sílabas, fundaron su versificación en el número determinado de éstas, en la disposición de los acentos y de las cesuras o pausas ${ }^{37}$. Pero, más adelante, se adhiere plenamente a la tesis cuantitativa, $y$ escribe que «las sílabas en castellano, lo mismo que en las demás lenguas, son largas o breves: es breve la sílaba en cuya pronunciación se emplea un tiempo, y larga en la que se emplean dos tiempos»; y, a renglón seguido, explica que «la $o$ de amo (yo) es breve, y en amó (aquél) es larga; y cualquiera advertirá que se emplea doble tiempo en la pronunciación de la segunda que en la de la primera» ${ }^{38}$.

En este espejismo de la duración silábica, y en la consiguiente distinción entre sílabas largas y breves, se verán involucrados en el siglo XIX, y aun en el Xx, no sólo los teóricos de la métrica, sino también algún poeta de la talla de Rubén Darío. Cuando el gran poeta nicaragüense intenta aclimatar a la métrica española el hexámetro clásico, piensa que con el juego saltarín de sus cláusulas rítmicas ternarias («Inclitas razas ubérrimas, sangre

\footnotetext{
${ }^{37}$ Mata i Araujo, Luis: Lecciones elementales de literatura, aplicadas especialmente a la castellana. Madrid: Norberto Llorencio, 1839, p. 236.

38 Ibid., pp. 353-354.
} 
de Hispania fecunda...») estaría insuflando una nueva vida al antiguo sistema combinatorio de las sílabas largas y breves. Y, así, afirma categóricamente, en 1909, que «malgré la opinión de tantos catedráticos, hay sílabas largas y breves, y que lo que ha faltado es un análisis más hondo y musical de nuestra prosodia» ${ }^{39}$.

Con toda seguridad, está Rubén Darío aludiendo, y también contradiciendo, a tratadistas como Andrés Bello y Eduardo Benot, que había publicado en 1892 un extenso tratado de métrica $^{40}$, en el que se rebaten una y otra vez los criterios cuantitativos. Tal vez la referencia a un análisis más musical de nuestra prosodia esté relacionada con las tesis defendidas por Sinibaldo de Mas, autor de un curioso libro titulado Sistema musical de la lengua castellana, cuya primera edición data de $1832^{41}$. Para Eduardo Benot, Sinibaldo de Mas fue uno de los «últimos representantes de lo antiguo» ${ }^{42}$, y censura repetidas veces sus «extravagantes reglas $\gg{ }^{43}$.

Parte Sinibaldo de Mas del supuesto de que las sílabas castellanas, al igual que las griegas y las latinas, pueden ser largas y breves, y formula a este respecto una serie de teoremas o reglas para medir la cantidad silábica, al tiempo que establece una lista de doscientas sílabas breves (tales con las de las palabras día, iría o ileso) y otras tantas sílabas largas (las de circunstancias, obstrucción o industrias). Escribe Benot que Sinibaldo de Mas «hacía leer ambas listas con el reloj en la mano a quien quiera que le negaba la existencia de breves y largas». En cualquier caso, «el experimento no evidenciaba que hubiese en castellano sílabas relacionadas entre sí $2: 1 »^{44}$.

Hay, sin embargo, una observación de Sinibaldo de Mas sobre la equivalencia de finales agudos, graves y esdrújulos, que

${ }^{39}$ Darío, Rubén: Historia de mis libros (1909), en Obras completas, t. I, Crítica y Ensayo. Madrid: Afrodisio Aguado, 1950, p. 216.

40 Benot, Eduardo: Prosodia castellana i versificación. Madrid: Pedro Núñez, [1892].

Ed. facsimilar al cuidado de Esteban Torre: Prosodia castellana y versificación.

Anejo I (2003) de Rhythmica, Revista Española de Métrica Comparada.

41 Vid. Mas, Sinibaldo de: Sistema musical de la lengua castellana. Ed. y estudio de José Domínguez Caparrós. Madrid: CSIC, 2001.

42 Benot, Eduardo: Prosodia castellana ..., cit., t. I, p. 166.

${ }^{43}$ Ibid., t. I, pp.184 y 394; y t. III, pp. 12, 18, 22 у 29.

44 Ibid., t. I, p. 183; y t. III, p. 15. 
se encuentra en franca oposición a los criterios cuantitativos y que merece ser destacada ${ }^{45}$. Para este autor, los versos Mil placeres nos vienen de Dios (de nueve sílabas), Mil placeres nos dieron los dioses (de diez sílabas) y Mil placeres nos dieron los números (de once sílabas) son equivalentes. "Generalmente se ha creído -advierte- que un verso en final agudo tenía una sílaba menos, porque dicho agudo es largo y vale por dos; pero esto es un error muy grave». La explicación del fenómeno, en efecto, «nada tiene que ver con la cantidad». Lo que ocurre es, sencillamente, que «el oído mide el verso por el último acento, y no por la última sílaba» ${ }^{46}$.

De inspiración musical es también la métrica de Miguel Agustín Príncipe, coetáneo de Sinibaldo de Mas. En su Arte métrica elemental ${ }^{47}$, dispuesta en forma de diálogo entre un joven aficionado a las Bellas Artes y el autor, nos habla de corcheas, semicorcheas, el «compás» y la «frase música». Como «frase música» entiende el verso desde la sílaba inicial hasta la última acentuada, esto es, el «conjunto o sucesión de sonidos que todo verso encierra como tal, a contar desde su primera sílaba hasta su postrera acentuada ${ }^{48}$. Rítmicamente, el verso termina en la última sílaba acentuada, «y esa sílaba es precisamente la en que termina la frase música, es decir, esa serie de sonidos que hacen que el verso sea ya en ella tal verso, independientemente de otras u otras sílabas que puedan añadirse al fin $\rangle^{49}$. Y es que, en efecto, «lo que esencialmente constituye al verso es solamente su frase música, o sea, el conjunto o sucesión de sus sonidos o sílabas, a contar desde la primera hasta su postrera acentuada ${ }^{50}$. Según esto, no debería ser el verso llano, sino el sono-final o agudo, el que se tomara como punto de referencia para la denominación de los versos castellanos. De este modo, el octosílabo debería

$\overline{45}$ Vid. TORRE, Esteban: «Sinibaldo de Mas: Sistema musical de la lengua castellana». Lexis, 2002, XXVI, 2, pp. 613-616.

${ }_{46}$ MAs, Sinibaldo de: Sistema musical..., cit., p. 49.

47 PrínCIPe, Miguel Agustín: Arte métrica elemental, o sea, tratado analítico de versificación castellana, en Fábulas en verso castellano y en variedad de metros. $2^{\mathrm{a}}$. ed. económica sin láminas. Madrid: Ibo Alfaro, 1862 [la $1^{\mathrm{a}}$ ed. con láminas es de 1861], pp. 385-662.

48 Ibid., p. 461.

49 Ibid., p. 462.

50 Ibid., p. 465. 
propiamente llamarse heptasílabo, el eneasílabo octosílabo, y así todos los demás ${ }^{51}$.

Acertada es la observación. Los versos de diez sílabas con terminación aguda, los de once sílabas de terminación llana y los de doce con terminación esdrújula tienen la misma medida rítmica, diez sílabas, hasta la última acentuada, y es por es esto por lo que son métricamente equivalentes. Los llamamos endecasílabos, ya que los de once sílabas de terminación llana son los más frecuentes en español, o en italiano. Pero los podríamos llamar también decasílabos, que es la denominación que encontramos precisamente en la métrica de algunas lenguas, como la inglesa (decasyllable), la portuguesa (decassílabo) o la catalana (decasíl.lab).

Joaquín Moreno Pedrosa, profesor universitario y poeta, ha publicado recientemente un valioso artículo sobre las poéticas contemporáneas $^{52}$, en el que se analiza la influencia de los conceptos musicales de Miguel Agustín Príncipe en la teoría métrica del también poeta y profesor Antonio Carvajal. Advierte Moreno Pedrosa que la medida y el ritmo de una composición musical «se basan en criterios absolutamente diferentes a los que rigen para el verso», y que el uso de los mismos términos, al igual que toda referencia a la «musicalidad» de los poemas, «sólo resulta aceptable como vaga analogía $\rangle^{53}$. Y es que Antonio Carvajal recoge los conceptos de compás y frase música de Miguel Agustín Príncipe; pero, como señala Moreno Pedrosa, prefiere atribuir la equivalencia de los finales agudos, llanos y esdrújulos a la duración de las sílabas. Así, en los finales agudos, habla de una mayor «resonancia» o duración del silencio que sigue a la sílaba final tónica, que estaría dotada de un acento «circunflejo ligado»; y, en los esdrújulos, se produciría una «síncopa». La palabra vendría a ser una especie de materia moldeable, plástica, elástica, que se podría expandir si termina en sílaba tónica, y

\footnotetext{
$\overline{51}$ Análogos criterios habrían de ser mantenidos más tarde por GRAÑA ETCHEVERRY, Manuel: «La equivalencia de los oxítonos, paroxítonos y proparoxítonos a fin de verso». Revista do Livro, 1957, II, 8, pp. 9-56.

52 Moreno Pedrosa, Joaquín: «El ritmo del verso en las poéticas contemporáneas: un ejemplo en la Generación del 70». Rhythmica, Revista Española de Métrica Comparada, 2014, XII, 12, pp. 109-124.

53 Ibid., p. 113.
} 
contraer si es tónica la penúltima. Moreno Pedrosa conceptúa justamente esta explicación como «de un marcado carácter impresionístico, y carente de verificación contrastable $\rangle^{54}$.

Las distintas explicaciones que, en la teoría métrica, se han venido dando a la equivalencia de los finales agudos, graves y esdrújulos han sido muy bien resumidas por José Domínguez Caparrós $^{55}$ :

a) Por la pervivencia de la antigua cantidad silábica, según la cual una sílaba «larga» (tónica) vale por dos «breves» (átonas).

b) Como un efecto de la pausa.

c) Como una prueba de que el verso termina realmente en la última sílaba acentuada.

El mismo autor hace también mención de ciertas investigaciones modernas, que, fundadas en mediciones experimentales, hablan de un desdoblamiento de la vocal tónica final o de una equivalencia de sensación temporal o de tiempo psicológico. Convendría analizar detenidamente las mencionadas investigaciones, ya que, como enseguida veremos, no son más que variantes del apartado a), esto es, una modernizada versión del empeño tradicional en fundamentar la equivalencia en la duración.

El desdoblamiento de la vocal tónica final, que ya defendía Vicente Salvá en el primer tercio del siglo XIX, la sido nuevamente invocado por María Josefa Canellada y Jens Koed Madsen $^{56}$. Para estas autoras, tras el estudio de numerosas grabaciones, existe un «alargamiento», que puede llegar a ser un auténtico «desdoblamiento» de la vocal final. Los principales informantes fueron un hablante catalán y una niña de dos años y tres meses. En el caso del hablante catalán, la vocal final, «con la correspondiente velarización» (al en social) permite que se pueda apreciar el desdoblamiento (sociáal). Por su parte, la niña,

$\overline{54}$ Ibid., p. 118. Vid. también Moreno Pedrosa, Joaquín: Poesía y poética de Antonio Carvajal. Sevilla: Padilla, 2007.

55 Domínguez CAPARrós, José: Contribución a la historia de las teorías métricas en los siglos XVII, XVIII y XIX. Madrid: CSIC, 1975, pp. 177-187; Métrica española. Madrid: Síntesis, 1993, pp. 72-73.

${ }^{56}$ Canellada, María Josefa, y Madsen, Jens Koed: Pronunciación del español. Lengua hablada y literaria. Madrid: Castalia, 1987. 
que está aprendiendo a leer distingue y silabea muy bien palabras como tío, tía. Pero, cuando ve por primera vez escritas palabras como papá, mamá, trata de leerlas, y pronuncia $p a-p a ́-a$, $m a-m a ́-a$. De ahí deducen, sin más, Canellada y Madsen que en el verso ocurre lo mismo que en el habla del niño: «la vocal tónica final se desdobla». No es preciso indicar que el valor probatorio de tales observaciones es nulo, y que, por supuesto, no es extrapolable al terreno de la métrica.

El intento de fundamentar en la duración el fenómeno de la equivalencia en la percepción de los versos oxítonos, paroxítonos y proparoxítonos aparece claramente en un trabajo de Antonio Quilis $^{57}$, quien llega a hablar de la cantidad silábica, y la mide en centésimas de segundo. Los resultados obtenidos tras la medición del tiempo en la lectura de una serie de versos conducen al reconocimiento de que «los valores no son absolutos» ${ }^{58}$, si bien existiría «una clara tendencia» hacia: 1) una mayor duración de la sílaba oxítona, y 2) una menor duración de las dos últimas sílabas de las palabras proparoxítonas.

De esta manera, la mayor duración de la sílaba oxítona justificaría la adición de una sílaba más en los versos de terminación aguda, y la menor duración de las dos sílabas postónicas nos llevaría al cómputo de una sílaba menos en los versos de terminación esdrújula. Al final del trabajo, se afirma que la equivalencia «no es de tiempo real, sino de sensación temporal»» ${ }^{59}$. Después de haber realizado una minuciosa cuantificación del tiempo cronológico, se recurre a la noción de tiempo psicológico o vivencial, concepto relativista que carece de toda aplicación práctica en lo que concierne al cómputo silábico.

${ }^{57}$ Quilis, Antonio: «La percepción de los versos oxítonos, paroxítonos y proparoxítonos en español». Revista de Filología Española, 1970, L, 1-4, pp. 273-286.

${ }^{58}$ El empeño en encontrar valores absolutos, con datos experimentales, aparece también en Gili GaYa, Samuel: «Introducción a los estudios ortológicos y métricos de Bello», en Obras completas. Estudios filológicos I, cit., p. LXXXVI: «Carecemos de comprobaciones experimentales que aclaren definitivamente la causa de que el acento agudo final de verso añada a éste una sílaba para el cómputo, y de que los finales esdrújulos valgan una sílaba menos».

59 Años después, se sigue sosteniendo que «la compensación temporal no es, evidentemente, de tiempo real, sino de percepción temporal». Vid. QuiLIs, Antonio: «Vigencia de las teorías ortológicas y métricas de Bello», en Homenaje a Andrés Bello en el bicentenario de su nacimiento (1781-1981), cit., p. 151. 
Más que en los criterios de la cantidad silábica, que no tiene en español ni en otras lenguas modernas justificación alguna, la explicación de la equivalencia de finales agudos, graves y esdrújulos ha de ser buscada en la concepción del verso como unidad rítmica, la consideración de la pausa como límite de la unión y la separación de los versos, y el reconocimiento del carácter culminante de la última sílaba acentuada. En esta última sílaba termina realmente el verso ${ }^{60}$, y así lo supieron ver Sinibaldo de Mas y Miguel Agustín Príncipe.

Andrés Bello, que tan certeramente supo apreciar la falta de pertinencia de la duración o cantidad en la medida del verso, no podía admitir el absurdo de que en los finales agudos la sílaba tónica valiera por dos, y en los finales esdrújulos las dos sílabas postónicas valieran por una. Justamente encontró en la pausa la explicación de la equivalencia versal. En la pausa se diluirían, se embeberían, la sílaba postónica de los finales graves y las dos sílabas postónicas de los finales esdrújulos. De ahí a reconocer que el verso, como unidad rítmica, termina en la última sílaba acentuada no hay más que un paso.

Para el filólogo venezolano, el lenguaje poético no es algo artificioso, alejado del lenguaje ordinario. Así, a propósito de la sinalefa, escribe que «esto se verifica no sólo en poesía, sino en el lenguaje ordinario, de cuya pronunciación no es lícito al poeta alejarse ${ }^{61}$. Y es tal «la propensión de nuestra lengua a la sinalefa» ${ }^{62}$, que ni los signos de puntuación, ni las pausas sintácticas que éstos señalan, se oponen a su realización. Es más, «entre dos dicciones, pronunciadas por diversos interlocutores en el drama,

$\overline{{ }^{60} \mathrm{E}}$ f factor determinante del ritmo no se sustenta en la duración silábica, ni en una pretendida isocronía acentual, ni en una supuesta isosilabia. El armazón rítmico del verso está constituido por sílabas y acentos, y la pausa es el factor demarcativo esencial, distinguiendo y separando los versos en la serie poemática. En virtud de la pausa, la última sílaba acentuada del verso adquiere un carácter culminante, por lo que el verso termina realmente en esta sílaba. Incluir en el cómputo silábico una sílaba más, postónica, en el caso de las terminaciones llanas, es algo que pertenece al dominio de lo convencional y forma parte del acervo de una tradición literaria. Vid. TORRe, Esteban: El ritmo del verso. Estudios sobre el cómputo silábico y la distribución acentual, a la luz de la Métrica Comparada, en el verso español moderno. Murcia: Universidad, 1999.

${ }_{61}$ Bello, Andrés: Principios de la ortología ..., cit., p. 229.

${ }^{62}$ Ibid., p. 235. 
es tan necesaria la sinalefa como en boca de una sola persona ${ }^{63}$.

En relación con el contacto entre vocales que pertenecen a distintas palabras, explica que, si no se produce la sinalefa, tiene lugar el hiato. Y, entre vocales que pertenecen a una misma palabra, pueden existir diptongos, o su disolución mediante la diéresis, así como hiatos, o su contracción mediante la sinéresis. No le pasa desapercibido al filólogo el hecho de que los dip-

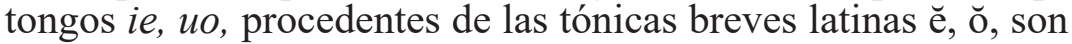
indisolubles:

Cuando los sonidos simples $e$, $o$, han pasado bajo la influencia del acento a los sonidos compuestos ié, ué, estas combinaciones forman diptongos absolutamente indisolubles, como sucede en diente, fuente, huerto, muerte, viento, nacidos de los vocablos latinos dente, fonte, horto, morte, vento, y en pienso, quiero, ruego, inflexiones de los verbos pensar, querer, rogar ${ }^{64}$.

Introduce Bello el concepto de cláusula rítmica: «Todas las cláusulas rítmicas que se usan en la versificación castellana son disílabas o trisílabas» ${ }^{65}$. Las primeras pueden ser trocaicas y yámbicas; las segundas, dactílicas, anfibráquicas y anapésticas. Y hace una distinción entre versos de rítmico trocaico y versos de ritmo yámbico. Entre los primeros se encontrarían el octosílabo, el hexasílabo y el tetrasílabo. Entre los segundos, el alejandrino a la francesa, el endecasílabo, el eneasílabo y el heptasílabo. En el verso endecasílabo «es de necesidad acentuar la 6. ${ }^{\mathrm{a}}$ y $10 .^{\mathrm{a}}$ sílaba, o la 4. ${ }^{\mathrm{a}}, 8 .^{\mathrm{a}}$ y $\left.10 .^{\mathrm{a}}\right\rangle{ }^{66}$.

Particular atención se le dedica al endecasílabo sáfico. Curiosamente, habrá que tener ahora en cuenta la cantidad silábica, aunque se advierte que no se trata aquí de hacer valer una sílaba larga por dos breves, sino que «la ligereza de las sílabas en determinados parajes da al verso un aire característico»:

Tenemos especies de versos en que es importante la cantidad silábica, por requerirse en ellas, además de ciertos acentos, que algunas de las sílabas inacentuadas sean breves; no porque sustituidas a éstas las

${ }_{63}$ Ibid., p. 236.
${ }^{64}$ Ibid., p. 207.
${ }^{65}$ Ibid., p. 273.
${ }^{66}$ Ibid., p. 318. 
largas variasen la medida o el ritmo, como en la versificación latina y griega, sino porque la ligereza de las sílabas en determinados parajes da al verso un aire característico. Los versos de esta especie que se usan más frecuentemente en castellano son el sáfico y el adónico. El sáfico es un endecasílabo que [...] debe acentuarse en la $4 .^{\mathrm{a}}, 8 .^{\mathrm{a}}$ y $10 .^{\mathrm{a}}$; pero en que se apetece además:

$1 .^{\circ}$ Un acento sobre la 1. ${ }^{\mathrm{a}}$ sílaba.

$2 .^{\circ}$ Que las sílabas 2. ${ }^{\mathrm{a}}$ y 3 . $^{\mathrm{a}}$ sean breves.

3. ${ }^{\circ}$ Que sean también breves la 6. ${ }^{\mathrm{a}}, 7 .^{\mathrm{a}}$ y $9 .^{\mathrm{a}}$ sílabas.

4. ${ }^{\circ}$ Que el primer hemistiquio termine en dicción grave.

$5 .^{\circ}$ Que no haya sinalefa en la cesura.

[...] He aquí un verso sáfico perfectamente regular:

Dulce vecino de la verde selva. (Villegas)

Además de los acentos indispensables de las sílabas $c i$, ver, sel, tenemos otro en $d u l$; la pronunciación se desliza con la mayor suavidad y ligereza sobre las sílabas $c e, v e, d e, l a, d e$; el primer hemistiquio termina en la dicción grave vecino, y no hay sinalefa entre los dos hemistiquios $\rangle^{67}$.

Es de advertir que Andrés Bello denomina «cesura» al corte que se produce tras la sílaba $5 .^{\mathrm{a}}$, habiendo de recaer el acento de la 4. ${ }^{\text {a }}$ sobre palabra llana (Dulce vecino / de la verde selva). Se trata propiamente de un verso simple bimembre, en el que Bello considera los dos miembros como «hemistiquios».

Sirva este breve recuerdo como homenaje al gran filólogo, poeta y metrista venezolano, que supo librar a la métrica castellana de algunos prejuicios y lastres que desgraciadamente han venido arrastrándose, en una buena parte, hasta nuestros días.

Para Andrés Bello, la prosodia del verso no es algo distinto de la del lenguaje ordinario, el oído debe primar siempre en su medida, y su enseñanza ha de basarse en la intuición y el ejercicio, más que en las lucubraciones y el mero afán especulativo y clasificatorio. Porque lo que verdaderamente importa en el verso es su lectura directa, su comprensión, su «audición», y el disfrute que esta lectura proporciona.

$\overline{{ }^{67}}$ Ibid., pp. 326-328. Andrés Bello, poeta, latinista y traductor de Horacio, pone en práctica estos preceptos con mayor o menor fortuna. Vid. Herrera MonTERo, Rafael: «Andrés Bello, traductor de una oda de Horacio». Cuadernos de Filología Clásica. Estudios latinos, 1995, 8, pp. 299-314. 